Research Paper

\title{
High neutrophil-to-lymphocyte ratio associated with progression to critical illness in older patients with COVID-19: a multicenter
} retrospective study

\author{
Jiangshan Lian ${ }^{1, *}$, Ciliang jin ${ }^{1,}{ }^{,}$,Shaorui Hao ${ }^{1, *}$, Xiaoli Zhang ${ }^{1, *}$, Meifang Yang ${ }^{1, *}$, Xi Jin ${ }^{2,}$, Yingfeng \\ $\mathrm{Lu}^{1}$, Jianhua $\mathrm{Hu}^{1}$, Shanyan Zhang ${ }^{1}$, Lin Zheng ${ }^{1}$, Hongyu Jia ${ }^{1}$, Huan $\mathrm{Cai}^{1}$, Yimin Zhang ${ }^{1}$, Guodong \\ $\mathrm{Yu}^{1}$, Xiaoyan Wang ${ }^{1}$, Jueqing $\mathrm{Gu}^{1}$, Chanyuan $\mathrm{Ye}^{1}$, Xiaopeng $\mathrm{Yu}^{1}$, Jianguo Gao ${ }^{2}$, Yida $\mathrm{Yang}^{1}$, Jifang \\ Sheng ${ }^{1}$ \\ ${ }^{1}$ State Key Laboratory for Diagnosis and Treatment of Infectious Diseases, National Clinical Research Center for \\ Infectious Diseases, Collaborative Innovation Center for Diagnosis and Treatment of Infectious Diseases, \\ Department of Infectious Diseases, The First Affiliated Hospital, College of Medicine, Zhejiang University, \\ Hangzhou, China \\ ${ }^{2}$ Department of Gastroenterology, The First Affiliated Hospital, College of Medicine, Zhejiang University, \\ Hangzhou, China \\ *Equal contribution
}

Correspondence to: Jifang Sheng, Yida Yang; email: jifang sheng@zju.edu.cn, yangyida65@163.com Keywords: SARS-CoV-2, COVID-19, older patients, neutrophil-to-lymphocyte ratio, risk factor

Received: May 2, 2020

Accepted: June 9, 2020

Published: July 30, 2020

Copyright: Lian et al. This is an open-access article distributed under the terms of the Creative Commons Attribution License (CC BY 3.0), which permits unrestricted use, distribution, and reproduction in any medium, provided the original author and source are credited.

\section{ABSTRACT}

This retrospective cohort study aimed to investigate the correlation of the neutrophil-to-lymphocyte ratio (NLR) with critical illness in older patients with COVID-19, and evaluate the prognostic power of the NLR at admission. We enrolled 232 patients with COVID-19, aged $\geq 60$ y, in Zhejiang province from January 17 to March 3, 2020. Primary outcomes were evaluated until April 13. Cox regression was performed for prognostic factors. Twentynine (12.5\%) patients progressed to critical illness. Age, shortness of breath, comorbidities including hypertension, heart disease, and chronic obstructive pulmonary disease, higher NLR, lower albumin levels, and multiple mottling and ground-glass opacity were associated with progression. In the multivariate analysis, older age (hazard ratio [HR] 1.121, confidence interval [CI] 1.070-1.174, $\mathrm{P}<0.001$ ), heart disease (HR 2.587, $\mathrm{Cl}$ 1.1565.787, $P=0.021$ ), higher NLR (HR 1.136, Cl 1.094-1.180, $P<0.001$ ), and multiple mottling and ground-glass opacity (HR 4.518, $\mathrm{Cl}$ 1.906-10.712, $\mathrm{P}<0.001$ ) remained critical illness predictors. The NLR was independently associated with progression to critical illness; the relationship was significant and graded (HR: 1.16 per unit; 95\% Cl: 1.10-1.22; P for trend < 0.001). Therefore, NLR can be adopted as a prognostic tool to assist healthcare providers predict the clinical outcomes of older patients suffering from COVID-19.

\section{INTRODUCTION}

In December 2019, a novel coronavirus called severe acute respiratory syndrome coronavirus 2 (SARS-CoV-2) was first identified in Wuhan, China [1-3]. Infection with the virus leads to coronavirus disease (COVID-19), which is characterized by rapid human-to-human transmission and varied degrees of fatality, due to acute respiratory distress syndrome, multi-organ failure, and other serious complications $[4,5]$. The global spread of this pandemic has been rapid since March 2020. As of mid-April 2020, more than 2 million individuals had been diagnosed with the disease, leading to over 150,000 deaths. 
In our previous study, we found that older patients with COVID-19 had significantly greater disease severities, as well as higher rates of critical-type disease and intensive care unit (ICU) admission than their younger counterparts outside Wuhan [6]. Wang et al. [7] found that patients treated in the ICU were older than those without ICU treatment in Wuhan. In the United States, Garg et al. [8] demonstrated that older adults had elevated rates of COVID-19-associated hospitalization, and the majority of people hospitalized with COVID-19 had underlying medical conditions. In Italy, a majority of critically ill patients with laboratory-confirmed COVID-19 who were admitted to ICUs were older men, and a large proportion of them required mechanical ventilation and high levels of positive end-expiratory pressure; the associated ICUrelated mortality was $26 \%$ [9].

Many studies have shown that older age is an independent risk factor for fatal outcomes in patients with COVID-19 [10-12]. Wang et al. investigated the characteristics of elderly patients with COVID-19 and the associated prognostic factors, and found that the presence of acute respiratory distress syndrome was a strong predictor of death. In addition, high lymphocyte levels were predictive of better outcomes [13]. Lymphopenia is a risk factor for severe illness and death among patients with COVID-19 [14].

The neutrophil-to-lymphocyte ratio (NLR) can be easily determined from the full blood count, and has been reported to be closely related to patients' overall inflammatory status.

Increasing NLR values are risk factors of mortality in not only infectious disease settings but also cancer $[15,16]$. A study showed that the NLR is an independent risk factor of mortality in hospitalized patients with COVID19 [17]. The identification of a good indicator of disease progression can aid clinicians in improving the effect of therapy and reducing the mortality related to COVID-19 without excessive medical resource use. Whether the NLR can predict progression to critical illness in older patients with COVID-19 requires further elucidated.

In this study, we investigated the correlation of the NLR with critical illness in older patients with COVID-19, to evaluate the prognostic power of the NLR at admission in the prediction of progression to critical illness.

\section{RESULTS}

\section{Demographic and epidemiologic characteristics}

In this study, 232 older ( $\geq 60$ years) patients with confirmed COVID-19 were enrolled from January 17, 2020 to March 3, 2020 in Zhejiang province. Patients' clinical outcomes were followed-up until April 13, 2020. As shown in Table 1, the median ages in the mild, severe, and critical disease groups were 66 years (interquartile range [IQR]: 63-70), 66 years (IQR: 6271 ) and 72 years (IQR: 68-81). The critical group showed a significantly higher age than the mild and severe groups $(P<0.001)$. The proportions of hypertension and heart disease in the critical group were $72.41 \%$ and $55.17 \%$, respectively, which were significantly higher than those noted in the mild and severe groups $(P<0.001)$. One case $(0.71 \%)$ with mild disease, two $(3.14 \%)$ with severe disease, and six $(20.69 \%)$ with critical disease had chronic obstructive pulmonary disease $(C O P D)(P<0.001)$. There were no significant differences in the other coexisting medical conditions across the three groups, including the rates of diabetes, asthma, cancer, chronic liver disease, chronic renal disease, and immunosuppression.

\section{Clinical features and laboratory abnormalities}

On admission, the majority of cases showed decreased or normal leucocyte levels in all subtypes, as shown in Table 2. The median neutrophil levels in the mild, severe, and critical groups were $3.22 \times 10^{9} / \mathrm{L}$ [IQR: $(2.59-4.20) \times 10^{9}$ ], $3.50 \times 10^{9} / \mathrm{L}$ [IQR: $(2.70-4.80) \times 10^{9}$ ] and $6.65 \times 10^{9} / \mathrm{L}$ [IQR: (3.51-9.70) $\times 10^{9}$ ], respectively; the critical group showed significantly higher values than the mild and severe groups $(\mathrm{P}<0.001)$. The median lymphocyte levels in the mild, severe, and critical groups were $1.26 \times 10^{9} / \mathrm{L}$ [IQR: $(0.90-$ 1.60) $\left.\times 10^{9}\right], 0.98 \times 10^{9} / \mathrm{L}$ [IQR: $\left.(0.70-1.26) \times 10^{9}\right]$, and $0.54 \times 10^{9} / \mathrm{L}$ [IQR: $(0.45-0.80) \times 10^{9}$ ], respectively. The critical group showed significantly lower values than the mild and severe groups $(\mathrm{P}<0.001)$. The platelet levels were lower in the critically group than the mild and severe groups, but were still within the normal range. The levels of lactate dehydrogenase, creatinine, C-reactive protein, and procalcitonin increased with increasing illness severity $(\mathrm{P}<0.05)$. There were no significant differences in the blood test results across the three groups, including the values of albumin, alanine aminotransferase, aspartate aminotransferase, total bilirubin, potassium, sodium, and blood urea nitrogen. Multiple mottling and ground-glass opacity were typical imaging manifestations noted in patients with COVID-19, and their prevalence rates in the mild, severe, and critical groups were $24.29 \%, 42.86 \%$, and $68.97 \%$, respectively $(P<0.001)$.

\section{Treatment and outcomes}

All patients were isolated in designated hospitals and received supportive care as well as the currently recommended medications. As shown in Table 3, 135 cases (84.77\%), 60 cases (95.24\%), and 29 cases $(100 \%)$ received antiviral treatment, including interferon- $\alpha$ sprays, arbidol hydrochloride capsules, and 
Table 1. Demographic, epidemiologic, and clinical characteristics of the different subtypes in older patients with COVID-19.

\begin{tabular}{|c|c|c|c|c|}
\hline Characteristic & Mild type $(n=140)$ & Severe type $(n=63)$ & Critical type $(n=29)$ & $P$ value \\
\hline Age (years) & $66(63-70)$ & $66(62-71)$ & $72(68-81)$ & $<0.001$ \\
\hline \multicolumn{5}{|l|}{ Distribution } \\
\hline $60-70$ y & $102(72.86)$ & $45(71.435)$ & $7(24.14)$ & $<0.001$ \\
\hline $70-80$ y & $30(21.43)$ & $14(22.22)$ & $13(44.83)$ & 0.025 \\
\hline$\geq 80 \mathrm{y}$ & $8(5.71)$ & $4(6.35)$ & $9(31.03)$ & $<0.001$ \\
\hline Sex (male) & $62(44.29)$ & $28(44.44)$ & $19(65.52)$ & 0.102 \\
\hline Body mass index $\left(\mathrm{kg} / \mathrm{m}^{2}\right)$ & $23.52(21.23-25.39)$ & $24.34(22.25-25.16)$ & $24.51(22.89-26.62)$ & 0.227 \\
\hline Current smoker & $17(12.14)$ & $4(6.35)$ & $4(13.79)$ & 0.418 \\
\hline Exposure history in Wuhan & $25(17.86)$ & $18(28.57)$ & $5(17.24)$ & 0.194 \\
\hline Contact with patients & $82(57.14)$ & $25(39.68)$ & 12(41.37) & 0.023 \\
\hline Family cluster & $50(35.71)$ & $20(31.75)$ & $10(34.48)$ & 0.859 \\
\hline $\begin{array}{l}\text { Time from illness onset to first } \\
\text { hospital admission (days) }\end{array}$ & $3(1-6)$ & $5(2-7)$ & $3(1-5)$ & 0.048 \\
\hline \multicolumn{5}{|l|}{ Coexisting disorder } \\
\hline Any & $76(54.29)$ & $25(38.68)$ & $13(44.83)$ & 0.132 \\
\hline Hypertension & $57(40.71)$ & $22(34.92)$ & $21(72.41)$ & 0.004 \\
\hline Heart disease & $8(5.71)$ & $7(11.11)$ & $16(55.17)$ & $<0.001$ \\
\hline Diabetes & $29(20.71)$ & $9(14.29)$ & $4(13.79)$ & 0.431 \\
\hline asthma & $1(0.71)$ & $1(1.59)$ & $2(6.90)$ & 0.076 \\
\hline Chronic obstructive pulmonary disease & $1(0.71)$ & $2(3.14)$ & $6(20.69)$ & $<0.001$ \\
\hline Cancer & $2(14.29)$ & $1(1.59)$ & $1(3.45)$ & 0.766 \\
\hline Chronic liver disease & $4(2.86)$ & $4(6.35)$ & $2(6.90)$ & 0.397 \\
\hline Chronic renal disease & $3(2.14)$ & $1(1.59)$ & $2(6.90)$ & 0.313 \\
\hline Immunosuppression & $0(0)$ & $2(3.17)$ & $0(0)$ & 0.064 \\
\hline \multicolumn{5}{|l|}{ Symptoms on admission } \\
\hline Fever & $110(78.57)$ & $55(87.30)$ & $25(86.21)$ & 0.105 \\
\hline Cough & $94(67.14)$ & $38(60.2)$ & $22(75.87)$ & 0.461 \\
\hline Sputum production & $46(32.86)$ & $26(41.27)$ & $15(51.72)$ & 0.148 \\
\hline Hemoptysis & $2(1.43)$ & $1(1.59)$ & $1(3.45)$ & 0.766 \\
\hline Sore throat & 13(9.29) & $8(12.70)$ & $2(6.90)$ & 0.598 \\
\hline Nasal obstruction & $2(1.43)$ & $0(0 \%)$ & $1(3.45)$ & 0.404 \\
\hline Myalgia & $12(8.57)$ & $8(12.70)$ & $4(13.79)$ & 0.552 \\
\hline Fatigue & $19(13.57)$ & $11(17.46)$ & $8(27.59)$ & 0.202 \\
\hline Gastrointestinal symptoms & $12(8.57)$ & $6(9.52)$ & $7(24.14)$ & 0.06 \\
\hline Headache & $5(3.57)$ & $6(9.52)$ & $0(0 \%)$ & 0.073 \\
\hline Shortness of breath & $1(0.71)$ & $7(11.11)$ & $12(41.38)$ & $<0.001$ \\
\hline
\end{tabular}

Data are presented as medians (interquartile ranges), $n(\%)$ and $n / N(\%)$.

lopinavir and ritonavir tablets in the mild, severe, and critical groups, respectively $(P=0.504)$. The durations from illness onset to antiviral therapy initiation were 4 days (IQR: 2.0-7.0), 5 days (IQR: 1.5-8.5), and 4 days
(IQR: 2.0-8.0) in the mild, severe, and critical groups, respectively $(P=0.390)$. With increases in the illness severity, the proportion of the use of glucocorticoids and intravenous immunoglobins rose $(P<0.001)$. Ten 
Table 2. Laboratory and radiograph findings of the different subtypes in older patients with COVID-19.

\begin{tabular}{|c|c|c|c|c|}
\hline Characteristic & Mild type (n=140) & Severe type $(n=63)$ & Critical type $(n=29)$ & $P$ value \\
\hline \multicolumn{5}{|l|}{ Blood routine } \\
\hline Leucocyte count $\left(\times 10^{9} / \mathrm{L}\right)$ & $5.20(4.38-6.48)$ & $5.0(4.1-6.88)$ & $8.08(4.4-10.8)$ & 0.02 \\
\hline Neutrophil count $\left(\times 10^{9} / \mathrm{L}\right)$ & $3.22(2.59-4.20)$ & $3.50(2.70-4.80)$ & $6.65(3.51-9.70)$ & $<0.001$ \\
\hline Lymphocyte count $\left(\times 10^{9} / \mathrm{L}\right)$ & $1.26(0.90-1.60)$ & $0.98(0.70-1.26)$ & $0.54(0.45-0.80)$ & $<0.001$ \\
\hline Neutrophil count/lymphocyte count & $2.45(1.82-3.65)$ & $4.08(2.39-6.20)$ & $9.67(6.86-21.10)$ & $<0.001$ \\
\hline Hemoglobin $(\mathrm{g} / \mathrm{L})$ & 125.0(113.0-138.0) & $122.0(113.5-133.5)$ & $121.0(110.5-137.5)$ & 0.535 \\
\hline Platelet count $\left(\times 10^{9} / \mathrm{L}\right)$ & 204(170-279) & $175(139-236)$ & $156(123-191)$ & $<0.001$ \\
\hline \multicolumn{5}{|l|}{ Coagulation function } \\
\hline International normalized ratio & $1.02(0.96-1.06)$ & $1.01(0.96-1.10)$ & $1.0(0.97-1.06)$ & 0.895 \\
\hline \multicolumn{5}{|l|}{ Blood biochemistry } \\
\hline Albumin $(\mathrm{g} / \mathrm{L})$ & $38.40(35.43-41.25)$ & $36.30(33.30-39.50)$ & $34.60(30.65-38.45)$ & 0.001 \\
\hline Alanine aminotransferase $(\mathrm{U} / \mathrm{L})$ & $25(16-36)$ & $24(16-31)$ & $21(14-31)$ & 0.664 \\
\hline Aspartate aminotransferase (U/L) & $25(20-33)$ & $25(19-34)$ & $29(18-38)$ & 0.891 \\
\hline Total bilirubin (umol//L) & $9.70(7.0-12.55)$ & $10.10(7.90-13.15)$ & $9.10(5.70-14.30)$ & 0.671 \\
\hline Potassium (mmol/L) & $3.99(3.70-4.37)$ & $3.89(3.45-4.25)$ & $3.81(3.50-4.14)$ & 0.072 \\
\hline Sodium $(\mathrm{mmol} / \mathrm{L})$ & $138.0(135.72-140.15)$ & $137.50(134.95-140.0)$ & 136.0(130.60-139.0) & 0.027 \\
\hline Blood urea nitrogen $(\mathrm{mmol} / \mathrm{L})$ & $4.51(3.83-5.47)$ & $4.59(3.60-7.10)$ & $6.16(4.48-8.72)$ & 0.032 \\
\hline Creatinine (umol/L) & $64.0(54.0-76.5)$ & $68.0(57.0-84.0)$ & $76.0(63.0-96.5)$ & 0.003 \\
\hline Creatinine kinase (U/L) & $56.50(41.25-88.75)$ & $62.0(26.25-113.75)$ & $80.0(52.0-173.50)$ & 0.038 \\
\hline Lactate dehydrogenase (U/L) & 218.0(175.0-256.50) & 233.0(190.0-313.0) & $273.0(243.0-354.0)$ & $<0.001$ \\
\hline \multicolumn{5}{|l|}{ Infection-related biomarkers } \\
\hline C-reactive protein $(\mathrm{mg} / \mathrm{L})$ & $16.02(4.41-39.26)$ & $19.10(5.89-44.70)$ & $41.86(6.33-70.10)$ & 0.039 \\
\hline Procalcitonin $(\mathrm{ng} / \mathrm{mL})$ & $0.09(0.04-0.14)$ & $0.05(0.04-0.08)$ & $0.19(0.04-0.25)$ & 0.046 \\
\hline \multicolumn{5}{|l|}{$\begin{array}{l}\text { Chest radiography/Computed } \\
\text { tomography findings }\end{array}$} \\
\hline $\begin{array}{l}\text { Multiple mottling and ground-glass } \\
\text { opacity }\end{array}$ & $34(24.29)$ & $27(42.86)$ & $20(68.97)$ & $<0.001$ \\
\hline
\end{tabular}

Data are presented as medians (interquartile ranges), $n(\%)$ and $n / N(\%)$.

patients received extracorporeal membrane oxygenation (ECMO) therapy, and six underwent continuous renalreplacement therapy (CRRT) in the critical group; none of the patients received ECMO therapy and only one underwent CRRT in the severe group. Three patients had shock in the critical group, while there were no cases with shock in the mild and severe groups $(P<0.001)$. The viral RNA shedding durations were 16 days (IQR: 12-22), 17 days (IQR: 14-21), and 25 days (IQR: 17-30) in the mild, severe, and critical groups, respectively $(\mathrm{P}<0.001)$.

By April 13, one patient had died, two had received lung transplantation, and eight remained hospitalized in the critical group. By May 27, among the eight patients who were still hospitalized, two withdrew from the ECMO treatment and were transferred to the general ward, while the other six patients were still receiving the ECMO therapy. In the other two groups, all patients had survived and were discharged. The number of days of hospitalization were 18 days [IQR: 14-23], 22 days [IQR: 19-26], and 32 days [IQR: 21-68] in the mild, severe, and critical groups, respectively $(\mathrm{P}<0.001)$.

\section{Risk factors associated with progression to critical illness}

Univariate Cox regression was used to analyze the risk factors for critical illness in the older patients with COVID-19, as shown in Table 4. Older age was shown to increase the likelihood of critical illness even in older patients ( $\geq 60$ years) (hazard ratio [HR] 1.107, confidence interval $[\mathrm{CI}] 1.065-1.151, \quad P<0.001)$. Shortness of breath as a symptom (HR 11.328, 
Table 3. Treatments and clinical outcomes of the different subtypes in older patients with COVID-19.

\begin{tabular}{lcccc}
\hline Characteristic & $\begin{array}{c}\text { Mild type } \\
(\mathbf{n = 1 4 0})\end{array}$ & $\begin{array}{c}\text { Severe type } \\
(\mathbf{n = 6 3})\end{array}$ & $\begin{array}{c}\text { Critical type } \\
(\mathbf{n = 2 9 )}\end{array}$ & $\boldsymbol{P}$ value \\
\hline Shock & $0(0)$ & $0(0)$ & $3(10.34)$ & $<0.001$ \\
Time from illness onset to antiviral treatment initiation (days) & $4.0(2.0-7.0)$ & $5.0(1.5-8.5)$ & $4.0(2.0-8.0)$ & 0.390 \\
Antiviral treatment & $135(96.43)$ & $60(95.24)$ & $29(100)$ & 0.504 \\
Viral RNA shedding time & $16(12-22)$ & $17(14-21)$ & $25(17-30)$ & $<0.001$ \\
Glucocorticoids & $22(15.71)$ & $29(46.03)$ & $26(89.66)$ & $<0.001$ \\
Use of intravenous immunoglobulin & 17() & 21() & $23(79.31)$ & $<0.001$ \\
Use of extracorporeal membrane oxygenation & $0(0)$ & $0(0)$ & $10(34.48)$ & $<0.001$ \\
Use of continuous renal-replacement therapy & $0(0)$ & $1(1.59)$ & $6(20.69)$ & $<0.001$ \\
Clinical outcomes at data cutoff & & & & \\
Discharge from hospital & $140(100)$ & $63(100)$ & $20(68.97)$ & 0.098 \\
Hospitalization & $0(0)$ & $0(0)$ & $8(27.59)$ & 0.098 \\
Number of days in hospital & $18(14-23)$ & $22(19-26)$ & $32(21-68)$ & $<0.001$ \\
Lung transplantation & $0(0)$ & $0(0)$ & $2(6.90)$ & 0.001 \\
Death & $0(0)$ & $0(0)$ & $1(3.45)$ & 0.030 \\
\hline
\end{tabular}

Data are presented as medians (interquartile ranges), $n(\%)$ and $n / N(\%)$.

Table 4. Risk factors for critical illness.

\begin{tabular}{lcccccc}
\hline \multirow{2}{*}{ Variables } & Mild/Severe type & Critical type & \multicolumn{2}{c}{ Univariate analysis } & \multicolumn{2}{c}{ Multivariate analysis } \\
\cline { 5 - 7 }$(\mathbf{n = 2 0 3})$ & $66(63-70)$ & $72(68-81)$ & $1.107(1.065-1.151)$ & $<0.001$ & $1.121(1.070-1.174)$ & $<0.001$ \\
\hline Age (years) & $3(1-7)$ & $3(1-5)$ & $0.937(0.836-1.049)$ & 0.258 & \\
Time from illness onset to first hospital & & & & & \\
admission (days) & $79(38.92)$ & $21(72.41)$ & $3.563(1.578-8.047)$ & 0.002 & \\
Hypertension & $15(7.39)$ & $16(55.17)$ & $9.638(4.626-20.081)$ & $<0.001$ & $2.587(1.156-5.787)$ & 0.021 \\
Heart disease & $3(1.48)$ & $6(20.69)$ & $7.108(2.891-17.481)$ & $<0.001$ & & \\
COPD & $8(3.94)$ & $12(41.38)$ & $11.328(5.370-$ & $<0.001$ & \\
Shortness of breath & & & $23.894)$ & & \\
& $2.68(1.96-4.42)$ & $9.67(6.86-21.10)$ & $1.157(1.117-1.199)$ & $<0.001$ & $1.136(1.094-1.180)$ & $<0.001$ \\
NLR & $38.0(35.20-41.0)$ & $34.60(30.65-38.45)$ & $0.875(0.807-0.950)$ & 0.001 & & \\
Albumin (g/L) & $16.95(4.75-40.62)$ & $41.86(6.33-70.10)$ & $1.012(1.005-1.020)$ & 0.002 & \\
C-reactive protein (mg/L) & $61(30.05)$ & $20(68.97)$ & $4.573(2.082-10.045)$ & $<0.001$ & $4.518(1.906-10.712)$ & 0.001 \\
Multiple mottling and ground-glass opacity & $61(30.05)$ &
\end{tabular}

$\mathrm{HR}$, hazard ratio; $\mathrm{Cl}$, confidence interval; COPD, chronic obstructive pulmonary disease; NLR, neutrophil-to-lymphocyte ratio.

CI 5.370-23.894, $\mathrm{P}<0.001)$, and comorbidities including hypertension (HR 3.563, CI 1.578-8.047, $P=0.002$ ), heart disease (HR 9.638, CI 4.626-20.081, $P<0.001$ ), and COPD (HR 7.108, CI 2.891-17.481, $P<0.001$ ) were predictive of critical illness. The increasing odds of critical illness development in patients with COVID-19 were associated with higher NLR values (HR 1.157, CI 1.117-1.199, $P<0.001$ ), lower albumin levels (HR 0.875 , CI $0.807-0.950, P<0.001)$, higher C-reactive protein levels (HR 1.012, CI 1.005-1.020, $P=0.002$ ), and multiple mottling and ground-glass opacity (HR 4.573, CI 2.082-10.045, P<0.001). In the multivariate analysis, only older age (HR 1.121, CI 1.070-1.174, $P<0.001$ ), heart disease (HR 2.587, CI 1.156-5.787,
$P=0.021$ ), higher NLRs (HR 1.136, CI 1.094-1.180, $P<$ 0.001 ), and multiple mottling and ground-glass opacity (HR 4.518, CI 1.906-10.712, $\mathrm{P}<0.001$ ) remained predictors of critical illness when the other factors in the model were kept constant.

\section{Association of the NLR with progression to critical illness}

Figure 1A shows the association between the NLR and progression to critical illness, as identified using a Cox proportional hazards model adjusted for the baseline covariates. For the sensitivity analysis, we converted the NLR from a continuous variable to a categorical 
variable (the quartile of NLR), and the P for trend of the NLR with categorical variables in the fully adjusted model (model II) was consistent with that obtained when the NLR was a continuous variable. The relationship between the NLR and progression was significant and graded (HR: 1.16 per unit; 95\% CI: $1.10-1.22 ; \mathrm{P}<0.001)$. When adjusted for sex and age, the ratio of the highest quartile of the NLR compared to the lowest quartile was 33.017 (95\% CI 4.436-245.732, P $<0.001$ ), and in the fully adjusted model, the odds of the NLR as a clinical risk factor was 21.755 (95\% CI 2.854165.860, $\mathrm{P}<0.001$ ) (Table 5). Figure $1 \mathrm{~B}$ shows the Kaplan-Meier analyses graphs for progression to critical illness based on the quartiles of the NLR.

\section{DISCUSSION}

In the present study, we described the clinical characteristics and outcomes of older patients who had COVID-19 with the highest risk of critical illness after SARS-CoV-2 infection. Of the 232 older patients with COVID-19, 29 (12.5\%) had critical disease; one patient died and two received lung transplantation in the critical group. Eight patients remained in the hospital, and received ECMO therapy for more than two weeks. The median duration of hospitalization was 32 days in the critical group, which was significantly longer than that in the mild and severe groups.

Disease typing and prognostic indicators are of great significance in the guidance of classified treatment and

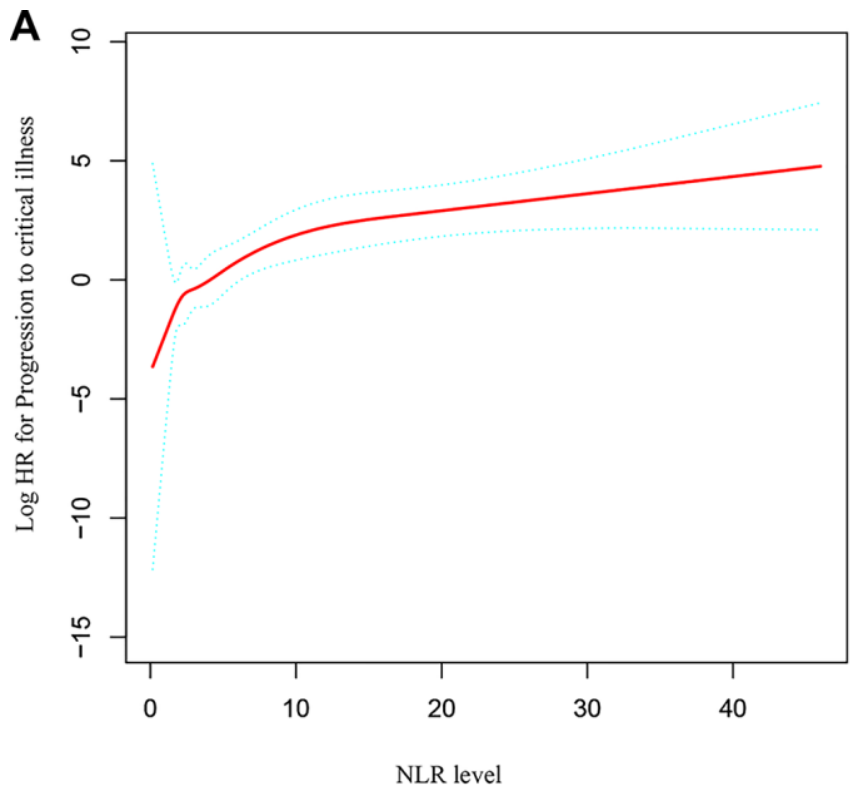

prevention of medical runs, and saving patients with a critical status. In our study, some independent risk factors for progression to critical illness were found using multivariate Cox regression analysis, such as older age, multiple mottling and ground-glass opacity, heart disease, and a high NLR.

Previously, older age was reported as an important independent predictor of fatal outcomes in patients with COVID-19 [18-21]. Older age was shown to increase the likelihood of critical illness even in older patients (HR 1.107, CI 1.065-1.151, P<0.001). Our results are consistent with those of previous reports [13]. Elderly patients experience a marked cell-mediated immune function decline and a reduced degree of humoral immune function. The cytokine and chemokine signaling networks are altered in elderly patients, and tend to favor a type 2 cytokine response over type 1 cytokine responses, potentially leading to poor outcomes [22].

Advanced imaging in patients with COVID-19 is capable of demonstrating disease progression. Generally, imaging manifestations are in line with the severity of COVID-19 [23]. Zhong et al. found that the computed tomography (CT) images in patients with different clinical types of COVID-19 had characteristic manifestations, and that the presence of solid shadows may be predictive of severe and critical illness [24]. Our study found that the presence of multiple mottling and ground-glass opacity on CT was an independent predictor of progression to critical illness (HR 4.518, CI

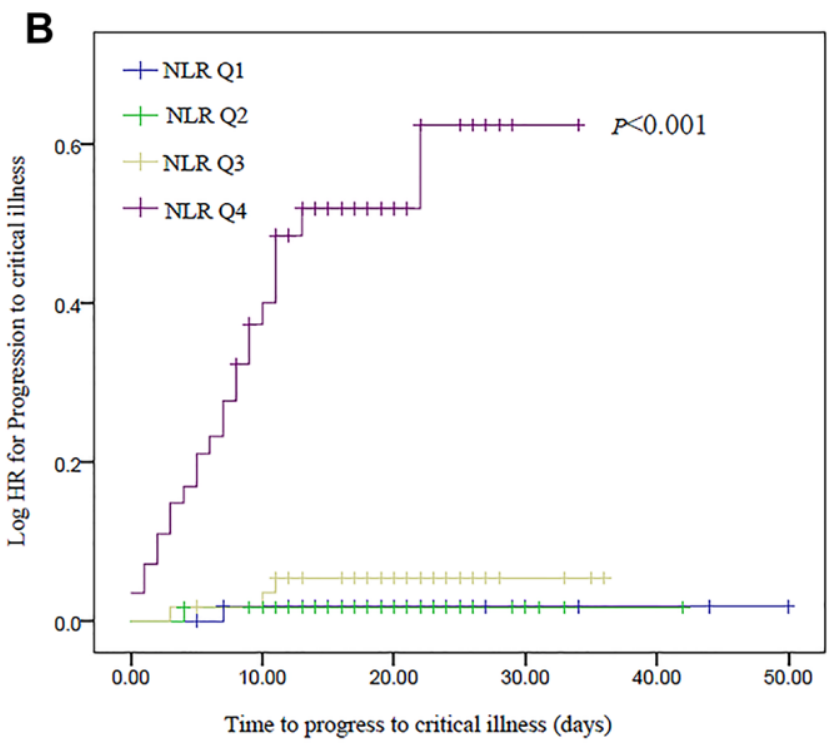

Figure 1. Association between the neutrophil-to-lymphocyte ratio (NLR) and progression to critical illness. (A) Adjusted hazard ratio (HR) for progression to critical illness according to the NLR. (B) Cumulative probability of progression to critical illness with increasing NLR values. 
Table 5. Relationships between the neutrophil-to-lymphocyte ratio and critical disease development using different models.

\begin{tabular}{lccccc}
\hline $\begin{array}{l}\text { Neutrophil-to-lymphocyte } \\
\text { ratio (quartile) }\end{array}$ & \multirow{2}{*}{ Total, $\mathbf{n}$} & \multirow{2}{*}{ Event $(\%)$} & \multicolumn{3}{c}{ HR (95\% CI) } \\
\cline { 4 - 6 } Q1 & 58 & $1(1.72)$ & Crude Model & Model I & Model II \\
Q2 & 60 & $1(1.61)$ & $0.980(0.061-15.662)$ & $1.186(0.074-18.984)$ & $1.324(0.081-21.591)$ \\
Q3 & 57 & $3(5.26)$ & $2.914(0.303-28.014)$ & $2.966(0.308-28.533)$ & $3.867(0.399-37.461)$ \\
Q4 & 57 & $24(42.11)$ & $29.769(4.024-$ & $33.017(4.436-$ & $21.755(2.854-$ \\
& & & $220.233)$ & $245.732)$ & $165.860)$ \\
$P$ for trend & - & - & $<0.001$ & $<0.001$ & $<0.001$ \\
Increase per unit & - & - & $1.16(1.12-1.20)$ & $1.15(1.11-1.19)$ & $1.16(1.10-1.22)$ \\
\hline
\end{tabular}

Note: Model I adjusted for age, sex.

Model II adjusted for age, sex, hypertension, heart disease, COPD, shortness of breath, albumin, C-reactive protein and multiple mottling and ground-glass opacity.

$\mathrm{HR}$, hazard ratio; $\mathrm{Cl}$, confidence interval; COPD, chronic obstructive pulmonary disease.

1.906-10.712, $P=0.001)$. We also found that older patients with COVID-19 who had heart disease were likelier to progress to critical illness. Several studies have shown that coexisting heart disease was an independent risk factor associated with fatal outcomes in patients with COVID-19 [12, 25]. Cardiac complications, including new or worsening heart failure, new or worsening arrhythmia, and myocardial infarction are commonly observed in patients with severe pneumonia. Cardiac arrest occurs in about 3\% of inpatients with severe pneumonia [26].

Chen et al. showed that, compared to cases with moderate disease severity, those with a severe disease status more frequently had lymphopenia [27]. Mo et al. found that patients with refractory disease had higher neutrophil levels than general COVID-19 patients [28]. The prognostic role of the NLR has been documented in multiple settings, including malignancies, infectious diseases, liver cirrhosis, and cerebrovascular disease [29-32]. In this study, we investigated the correlation of the NLR with critical illness in older patients with COVID-19 to evaluate the prognostic power of the NLR at admission in the prediction of progression to critical illness. In the sensitivity analysis, we converted the NLR from a continuous variable to a categorical variable, and found that the higher the NLR the greater the likelihood of progression to critical illness. Liu et al. also found that the NLR is an independent risk factor of in-hospital mortality in COVID-19 patients, especially male patients [17]. Our previous study suggested that a change in the NLR on admission among older patients with COVID-19 might be a biomarker specific to the prediction of progression to critical illness. A future study, conducted to elucidate this specificity, will further our understanding of the prognostic value of the NLR.
Our study has several limitations. First, its retrospective nature may decrease the accuracy of the findings; there is a need for a validation cohort to assess the predictive accuracy and confirm our findings. Second, owing to the retrospective design, data on some relevant factors such as interleukin-6 and D-dimer were incomplete and could not be included in the risk factor analysis. Third, data on the outcomes of older patients with COVID-19 in the critical group require further investigation, as, at the time of this study, there were still eight patients who were undergoing treatment at the hospital.

\section{MATERIALS AND METHODS}

\section{Patients}

This retrospective study, focusing on the epidemiological and clinical characteristics of older (age $\geq 60$ years) patients with confirmed COVID-19, was conducted from January 17 to March 3, 2020. All the enrolled cases showed real-time reverse transcriptase polymerase chain reaction (RT-PCR) positivity for SARS-CoV-2, and were retested several times during their hospitalization. Data were collected uniformly by the Health Commission of Zhejiang Province, wherein all patients were assigned to specific hospitals for unified treatment according to Zhejiang Province's emergency rule. The diagnosis of COVID-19 infection was based on the interim guidance of the World Health Organization (WHO) [33], and all data were shared with the WHO, with the primary analytic results reported to the authority of Zhejiang Province. Since the collection and analysis of all cases were determined by the Health Commission of Zhejiang Province under national authorization and considered as part of the continuing public health outbreak investigation, our retrospective study was exempt from institutional review board approval. 
The subtype definition of COVID-19 patients was based on the diagnosis and treatment scheme for COVID-19 in China, based on a minor modification of WHO standards [34]. The degree of COVID-19 was categorized as mild, severe, or critical: the mild type included non-pneumonia and mild pneumonia cases, and the severe type was characterized by dyspnea, respiratory frequency $\geq 30 \mathrm{~min}$, blood oxygen saturation $\leq 93 \%, \mathrm{PaO} 2 / \mathrm{FiO} 2$ ratio $<300$, and/or rate of lung infiltration $>50 \%$ within $24-48 \mathrm{~h}$. Critical cases were those that exhibited respiratory failure, septic shock, and/or multiple organ dysfunction/failure.

\section{Procedures}

We obtained epidemiological, demographic, laboratory, clinical, management, and outcome data from patients' medical records. Data were retrieved and reviewed by two independent observers. Clinical outcomes were followed-up until April 13, 2020. Missing or unclear data were confirmed by direct communication with healthcare providers. Throat swab specimens obtained from the upper respiratory tract and sputum of all patients were collected at admission. Laboratory confirmation of COVID-19 was performed at the First Affiliated Hospital at Zhejiang University, under the authorization of the Centers for Disease Control and Prevention at the Zhejiang Province/city level, by previously reported RT-PCR methods. All patients underwent chest CT at admission. Patients with other common respiratory viruses, including respiratory syncytial virus, parainfluenza virus, influenza A and B virus, and adenovirus were excluded from this study.

\section{Data collection}

In this study, we collected data on epidemiology, anthropometrics, demographics, as well as symptoms and signs at the time of admission to the hospital. We analyzed the blood collected within 48 hours of admission. Additional data collected included those on the results of laboratory tests and chest CT, comorbidities, co-infection with other respiratory pathogens, treatment (including drugs, intensive care and mechanical ventilation), and other clinical outcomes.

\section{Statistical analysis}

Continuous variables are expressed as medians (range), and were compared using $\mathrm{t}$ tests or Mann-Whitney U tests, and categorical variables were compared using chi-squared tests or Fisher's exact tests. Follow-up was initiated on the day of admission, and ended at the patient's death or until the last follow-up. The Kaplan-Meier method was used to evaluate the cumulative rate of progression to critical illness, and a log-rank test was used to assess differences between groups. HRs were calculated using the Cox regression model. Variables with $P<0.05$ in the univariate analysis were included in a stepwise Cox proportional hazards regression model. We performed tests for linear trend by entering the median value of each quartile of the NLR as a continuous variable in the models. The Cox proportional hazards model was used to estimate the HRs associated with the NLR for the risk of progression to critical illness with adjustment for pertinent variables. The HRs and 95\% CIs of the progression to critical illness in each subgroup were estimated, and their interactions tested. Statistical analyses were conducted using SPSS version 26.0 (IBM Corporation, Armonk) and $\mathrm{R}$ version 3.4 (R Foundation). A two-sided $P$ value $<0.05$ was considered to indicate statistical significance.

\section{ACKNOWLEDGMENTS}

We thank the Health Commission of Zhejiang Province, China for coordinating data collection. We are grateful to all the front-line medical staffs of Zhejiang Province for their bravery and efforts in COVID-19 prevention and control.

\section{CONFLICTS OF INTEREST}

There are no conflicts of interest to declare.

\section{FUNDING}

This work was supported by National Major Science and Technology Research Projects for the Control and Prevention of Major Infectious Diseases in China (2017ZX10202202001005; 2017ZX10204401001002) and Zhejiang University Education Foundation (2020 XGZX101).

\section{REFERENCES}

1. Huang $C$, Wang $Y$, Li $X$, Ren L, Zhao J, Hu Y, Zhang L, Fan G, Xu J, Gu X, Cheng Z, Yu T, Xia J, et al. Clinical features of patients infected with 2019 novel coronavirus in Wuhan, China. Lancet. 2020; 395:497-506. https://doi.org/10.1016/S0140-6736(20)30183-5 PMID:31986264

2. Li Q, Guan $X$, Wu P, Wang $X$, Zhou L, Tong $Y$, Ren R, Leung KS, Lau EH, Wong JY, Xing X, Xiang N, Wu Y, et al. Early transmission dynamics in Wuhan, China, of novel coronavirus-infected pneumonia. N Engl J Med. 2020; 382:1199-207. https://doi.org/10.1056/NEJMoa2001316 PMID:31995857

3. Zhu N, Zhang D, Wang W, Li X, Yang B, Song J, Zhao X, Huang B, Shi W, Lu R, Niu P, Zhan F, Ma X, et al, and China Novel Coronavirus Investigating and Research 
Team. A novel coronavirus from patients with pneumonia in China, 2019. N Engl J Med. 2020; 382:727-33.

https://doi.org/10.1056/NEJMoa2001017 PMID:31978945

4. Chen N, Zhou M, Dong X, Qu J, Gong F, Han Y, Qiu Y, Wang J, Liu Y, Wei Y, Xia J, Yu T, Zhang X, Zhang L. Epidemiological and clinical characteristics of 99 cases of 2019 novel coronavirus pneumonia in Wuhan, China: a descriptive study. Lancet. 2020; 395:507-13. https://doi.org/10.1016/S0140-6736(20)30211-7 PMID: $\underline{32007143}$

5. Chan JF, Yuan S, Kok KH, To KK, Chu H, Yang J, Xing F, Liu J, Yip CC, Poon RW, Tsoi HW, Lo SK, Chan KH, et al. A familial cluster of pneumonia associated with the 2019 novel coronavirus indicating person-to-person transmission: a study of a family cluster. Lancet. 2020; 395:514-23.

https://doi.org/10.1016/S0140-6736(20)30154-9

PMID:31986261

6. Lian J, Jin X, Hao S, Cai H, Zhang S, Zheng L, Jia H, Hu J, Gao J, Zhang Y, Zhang X, Yu G, Wang X, et al. Analysis of epidemiological and clinical features in older patients with corona virus disease 2019 (COVID-19) out of Wuhan. Clin Infect Dis. 2020. [Epub ahead of print]. https://doi.org/10.1093/cid/ciaa242 PMID:32211844

7. Wang $D, H u B, H u ~ C$, Zhu F, Liu X, Zhang J, Wang B, Xiang $\mathrm{H}$, Cheng Z, Xiong $\mathrm{Y}$, Zhao $\mathrm{Y}$, Li Y, Wang X, Peng Z. Clinical characteristics of 138 hospitalized patients with 2019 novel coronavirus-infected pneumonia in Wuhan, China. JAMA. 2020; 323:1061-69.

https://doi.org/10.1001/jama.2020.1585

PMID:32031570

8. Garg S, Kim L, Whitaker M, O'Halloran A, Cummings C, Holstein R, Prill M, Chai SJ, Kirley PD, Alden NB, Kawasaki B, Yousey-Hindes K, Niccolai L, et al. Hospitalization rates and characteristics of patients hospitalized with laboratory-confirmed coronavirus disease 2019 - COVID-NET, 14 states, March 1-30, 2020. MMWR Morb Mortal Wkly Rep. 2020; 69:458-64. https://doi.org/10.15585/mmwr.mm6915e3 PMID:32298251

9. Grasselli $G$, Zangrillo A, Zanella A, Antonelli M, Cabrini L, Castelli A, Cereda D, Coluccello A, Foti G, Fumagalli R, lotti G, Latronico N, Lorini L, et al, and COVID-19 Lombardy ICU Network. Baseline characteristics and outcomes of 1591 patients infected with SARS-CoV-2 admitted to ICUs of the lombardy region, Italy. JAMA. 2020; 323:1574-81.

https://doi.org/10.1001/jama.2020.5394 PMID: $\underline{32250385}$

10. Gong J, Ou J, Qiu X, Jie Y, Chen Y, Yuan L, Cao J, Tan M, $\mathrm{Xu} \mathrm{W}$, Zheng F, Shi Y, Hu B. A tool to early predict severe corona virus disease 2019 (COVID-19): a multicenter study using the risk nomogram in Wuhan and guangdong, China. Clin Infect Dis. 2020. [Epub ahead of print].

https://doi.org/10.1093/cid/ciaa443

PMID:32296824

11. Wynants L, Van Calster B, Collins GS, Riley RD, Heinze G, Schuit E, Bonten MM, Damen JA, Debray TP, De Vos M, Dhiman P, Haller MC, Harhay MO, et al. Prediction models for diagnosis and prognosis of covid-19 infection: systematic review and critical appraisal. BMJ. 2020; 369:m1328.

https://doi.org/10.1136/bmj.m1328 PMID:32265220

12. Chen $R$, Liang $W$, Jiang $M$, Guan $W$, Zhan $C$, Wang $T$, Tang C, Sang L, Liu J, Ni Z, Hu Y, Liu L, Shan H, et al, and Medical Treatment Expert Group for COVID-19. Risk factors of fatal outcome in hospitalized subjects with coronavirus disease 2019 from a nationwide analysis in China. Chest. 2020; 158:97-105.

https://doi.org/10.1016/j.chest.2020.04.010 PMID:32304772

13. Wang L, He W, Yu X, Hu D, Bao M, Liu H, Zhou J, Jiang H. Coronavirus disease 2019 in elderly patients: characteristics and prognostic factors based on 4-week follow-up. J Infect. 2020; 80:639-45.

https://doi.org/10.1016/j.jinf.2020.03.019 PMID:32240670

14. Chen T, Wu D, Chen H, Yan W, Yang D, Chen G, Ma K, Xu D, Yu H, Wang H, Wang T, Guo W, Chen J, et al. Clinical characteristics of 113 deceased patients with coronavirus disease 2019: retrospective study. BMJ. 2020; 368:m1091. https://doi.org/10.1136/bmj.m1091 PMID:32217556

15. Jia W, Wu J, Jia H, Yang Y, Zhang X, Chen K, Su F. The peripheral blood neutrophil-to-lymphocyte ratio is superior to the lymphocyte-to-monocyte ratio for predicting the long-term survival of triple-negative breast cancer patients. PLoS One. 2015; 10:e0143061. https://doi.org/10.1371/journal.pone.0143061 PMID:26580962

16. Choi JE, Villarreal J, Lasala J, Gottumukkala V, Mehran RJ, Rice D, Yu J, Feng L, Cata JP. Perioperative neutrophil:lymphocyte ratio and postoperative NSAID use as predictors of survival after lung cancer surgery: a retrospective study. Cancer Med. 2015; 4:825-33. https://doi.org/10.1002/cam4.428 PMID:25756351

17. Liu Y, Du X, Chen J, Jin Y, Peng L, Wang HH, Luo M, Chen L, Zhao Y. Neutrophil-to-lymphocyte ratio as an independent risk factor for mortality in hospitalized patients with COVID-19. J Infect. 2020; 81:e6-12.

https://doi.org/10.1016/j.jinf.2020.04.002

PMID:32283162 
18. Du RH, Liang LR, Yang CQ, Wang W, Cao TZ, Li M, Guo GY, Du J, Zheng CL, Zhu Q, Hu M, Li XY, Peng P, Shi HZ. Predictors of mortality for patients with COVID-19 pneumonia caused by SARS-CoV-2: a prospective cohort study. Eur Respir J. 2020; 55:2000524.

https://doi.org/10.1183/13993003.00524-2020 PMID:32269088

19. Liang WH, Guan WJ, Li CC, Li YM, Liang HR, Zhao Y, Liu $X Q$, Sang L, Chen RC, Tang CL, Wang T, Wang W, He $\mathrm{QH}$, et al. Clinical characteristics and outcomes of hospitalised patients with COVID-19 treated in Hubei (epicentre) and outside Hubei (non-epicentre): a nationwide analysis of China. Eur Respir J. 2020; 55:2000562.

https://doi.org/10.1183/13993003.00562-2020

PMID:32269086

20. Zhang JJ, Dong $X$, Cao YY, Yuan YD, Yang YB, Yan YQ, Akdis CA, Gao YD. Clinical characteristics of 140 patients infected with SARS-CoV-2 in Wuhan, China. Allergy. 2020; 75:1730-1741. https://doi.org/10.1111/all.14238 PMID:32077115

21. Zhou F, Yu T, Du R, Fan G, Liu Y, Liu Z, Xiang J, Wang Y, Song B, Gu X, Guan L, Wei Y, Li H, et al. Clinical course and risk factors for mortality of adult inpatients with COVID-19 in Wuhan, China: a retrospective cohort study. Lancet. 2020; 395:1054-62.

https://doi.org/10.1016/S0140-6736(20)30566-3

PMID:32171076

22. Opal SM, Girard TD, Ely EW. The immunopathogenesis of sepsis in elderly patients. Clin Infect Dis. 2005 (Suppl 7); 41:S504-12. https://doi.org/10.1086/432007 PMID:16237654

23. Chung $M$, Bernheim $A$, Mei $X$, Zhang $N$, Huang $M$, Zeng $X$, Cui J, Xu W, Yang Y, Fayad ZA, Jacobi A, Li K, Li S, Shan H. CT imaging features of 2019 novel coronavirus (2019-nCoV). Radiology. 2020; 295:202-07. https://doi.org/10.1148/radiol.2020200230 PMID:32017661

24. Zhong $Q$, Li Z, Shen $X$, Xu K, Shen $Y$, Fang $Q$, Chen $F$, Liang T. [CT imaging features of patients with different clinical types of coronavirus disease 2019 (COVID-19)]. Zhejiang Da Xue Xue Bao Yi Xue Ban. 2020; 49:0. PMID:32207591

25. Du $Y$, Tu L, Zhu $P$, Mu M, Wang R, Yang $P$, Wang $X$, Hu C, Ping R, Hu P, Li T, Cao F, Chang C, et al. Clinical features of 85 fatal cases of COVID-19 from Wuhan. A retrospective observational study. Am J Respir Crit Care Med. 2020; 201:1372-79. https://doi.org/10.1164/rccm.202003-05430C PMID:32242738
26. Marrie TJ, Shariatzadeh MR. Community-acquired pneumonia requiring admission to an intensive care unit: a descriptive study. Medicine (Baltimore). 2007; 86:103-11.

https://doi.org/10.1097/MD.0b013e3180421c16 PMID: 17435590

27. Chen G, Wu D, Guo W, Cao Y, Huang D, Wang H, Wang $\mathrm{T}$, Zhang $\mathrm{X}$, Chen $\mathrm{H}$, Yu H, Zhang $\mathrm{X}$, Zhang $\mathrm{M}$, Wu S, et al. Clinical and immunological features of severe and moderate coronavirus disease 2019. J Clin Invest. 2020; 130:2620-29.

https://doi.org/10.1172/JCl137244 PMID:32217835

28. Mo $P$, Xing $Y$, Xiao $Y$, Deng $L$, Zhao $Q$, Wang $H$, Xiong $Y$, Cheng Z, Gao S, Liang K, Luo M, Chen T, Song S, et al. Clinical characteristics of refractory COVID-19 pneumonia in Wuhan, China. Clin Infect Dis. 2020. [Epub ahead of print]. https://doi.org/10.1093/cid/ciaa270 PMID: $\underline{32173725}$

29. Zhang HF, Ge YL, Wang HY, Zhang Q, Li WQ, Chen $Y$, Chen QC, Jin JJ, Xu J, Zhang S, Xu TT, Zhang X, Yu HL, et al. Neutrophil-to-lymphocyte ratio improves the accuracy and sensitivity of pneumonia severity index in predicting 30-day mortality of CAP patients. Clin Lab. 2019; 65.

https://doi.org/10.7754/Clin.Lab.2019.190226 PMID:31625349

30. Zhang F, Ren Y, Fu W, Wang Y, Qian J, Tao C, You C, Yang M. Association between neutrophil to lymphocyte ratio and blood glucose level at admission in patients with spontaneous intracerebral hemorrhage. Sci Rep. 2019; 9:15623.

https://doi.org/10.1038/s41598-019-52214-5 PMID:31666624

31. Deng $Y$, Fan X, Ran $Y, X u X$, Lin L, Cui B, Hou L, Zhao T, Wang $Y$, Su Z, Jiang $X$, Zhao W, Wang B, Sun C. Prognostic impact of neutrophil-to-lymphocyte ratio in cirrhosis: a propensity score matching analysis with a prespecified cut-point. Liver Int. 2019; 39:2153-63. https://doi.org/10.1111/liv.14211 PMID:31408916

32. Bartlett EK, Flynn JR, Panageas KS, Ferraro RA, Sta Cruz JM, Postow MA, Coit DG, Ariyan CE. High neutrophilto-lymphocyte ratio (NLR) is associated with treatment failure and death in patients who have melanoma treated with PD-1 inhibitor monotherapy. Cancer. 2020; 126:76-85. https://doi.org/10.1002/cncr.32506 PMID:31584709

33. WHO. Clinical management of severe acute respiratory infection when Novel coronavirus (nCoV) infection is suspected: interim guidance. 2020. https://apps.who.int/iris/handle/10665/330893

34. Wu Z, McGoogan JM. Characteristics of and important lessons from the coronavirus disease 2019 (COVID-19) 
outbreak in China: summary of a report of 72314 cases from the Chinese center for disease control and prevention. JAMA. 2020. [Epub ahead of print].

https://doi.org/10.1001/jama.2020.2648

PMID:32091533 